\title{
Stable Isotope Labeling by Amino Acids in Cell Culture (SILAC)-Based Quantitative Proteomics and Phosphoproteomics in Fission Yeast
}

\author{
Alejandro Carpy, ${ }^{1}$ André Koch, ${ }^{2,4}$ Claudia C. Bicho, ${ }^{3,5}$ Weronika E. Borek, ${ }^{3}$ Silke Hauf,, 6 \\ Kenneth E. Sawin, ${ }^{3,7}$ and Boris Maček ${ }^{1,7}$ \\ ${ }^{1}$ Proteome Center Tuebingen, Interfaculty Institute for Cell Biology, University of Tuebingen, 72076 Tuebingen, \\ Germany; ${ }^{2}$ Friedrich Miescher Laboratory of the Max Planck Society, Tuebingen 72076, Germany; ${ }^{3}$ Wellcome \\ Trust Centre for Cell Biology, School of Biological Sciences, University of Edinburgh, Edinburgh EH9 3BF, \\ United Kingdom
}

Modern mass spectrometry (MS)-based approaches are capable of identifying and quantifying thousands of proteins and phosphorylation events in a single biological experiment. Here we present a (phospho)proteomic workflow based on in-solution proteome digestion of samples labeled by stable isotope labeling by amino acids in cell culture (SILAC) and phosphopeptide enrichment using strong cation exchange (SCX) and $\mathrm{TiO}_{2}$ chromatographies. These procedures are followed by high-accuracy MS measurement on an Orbitrap mass spectrometer and subsequent bioinformatic processing using MaxQuant software.

It is essential that you consult the appropriate Material Safety Data Sheets and your institution's Environmental Health and Safety Office for proper handling of equipment and hazardous material used in this protocol.

RECIPES: Please see the end of this protocol for recipes indicated by $<R>$. Additional recipes can be found online at http://cshprotocols.cshlp.org/site/recipes.

Reagents

Acetonitrile (ACN) (as needed; see Step 17)

Alkylation buffer (with IAA [iodoacetic acid]) $<\mathrm{R}>$

Denaturation buffer $<\mathrm{R}>$

Elution solution $<\mathrm{R}>$

Formic acid

$\mathrm{H}_{2} \mathrm{O}$ (high-purity, deionized [i.e., Milli-Q])

HPLC (high-performance liquid chromatography) loading solvent $<\mathrm{R}>$

\footnotetext{
${ }^{4}$ Present address: The Netherlands Cancer Institute, 1066 CX Amsterdam, The Netherlands

${ }^{5}$ Present address: Department of Cell and Tissue Biology, University of California San Francisco, San Francisco, California 94143

${ }^{6}$ Present address: Department of Biological Sciences and Virginia Bioinformatics Institute, Virginia Polytechnic Institute and State University, Blacksburg, Virginia 24061

${ }^{7}$ Correspondence: ken.sawin@ed.ac.uk; boris.macek@uni-tuebingen.de

From the Fission Yeast collection, edited by lain M. Hagan, Antony M. Carr, Agnes Grallert, and Paul Nurse.

(C) 2017 Cold Spring Harbor Laboratory Press

Cite this protocol as Cold Spring Harb Protoc; doi:10.1101/pdb.prot091686
} 
HPLC solvent $\mathrm{A}<\mathrm{R}>$

HPLC solvent $\mathrm{B}<\mathrm{R}>$

Lysyl endopeptidase LysC

Protein samples from Protocol: Construction, Growth, and Harvesting of Fission Yeast Stable

Isotope Labeling by Amino Acids in Cell Culture (SILAC) Strains (Koch et al. 2016)

This protocol is optimized for protein amounts between 2 and $10 \mathrm{mg}$. We recommend using at least $5 \mathrm{mg}$ of protein to achieve good coverage of the phosphoproteome.

Reduction buffer (with DTT) $<$ R $>$

SCX (strong cation exchange) solvent $\mathrm{A}<\mathrm{R}>$

SCX solvent $\mathrm{B}<\mathrm{R}>$

$\mathrm{TiO}_{2}$ loading solution (freshly prepared) $<\mathrm{R}>$

Trifluoroacetic acid (TFA)

Tris- $\mathrm{HCl}$ (1 M, pH 8.0) (as needed)

Trypsin (sequencing grade, modified) (as needed; see Step 7)

Washing solution for $\mathrm{TiO}_{2}$ beads (freshly prepared) $<\mathrm{R}>$

Equipment

Benchtop shaker

Centrifuge

Centrifuge tubes

Empore C-8 extraction disk (3M 98060402140)

For Step 26, prepare one C8 microcolumn ("stage-tip") for each sample by placing an 1-mm ${ }^{2}$ piece of Empore C8 material into a 200- $\mu$ L (yellow) pipette tip as described previously (Rappsilber et al. 2007). C8 microcolumns can also be commercially obtained (Thermo Fisher Scientific SP301).

Empore C-18 extraction disk (3M 98060402173)

For Step 32, prepare one C18 microcolumn for each sample as described for C8 microcolumns above, but using Empore C18 material.

Fast protein liquid chromatography (FPLC) system and Orbitrap mass spectrometer

This protocol has been performed using an Easy-nLC II system connected to an LTQ Orbitrap Elite (Thermo Fisher Scientific) using a nano-electrospray source; however, any nanoflow liquid chromatography system connected to a high-resolution mass spectrometer can be used. In addition, although this method was developed with an HPLC system, an UHPLC system is equally effective; simply adjust the parameters in Step 37 accordingly.

Lyophilizer

MaxQuant software suite

We routinely use the MaxQuant software suite (Cox and Mann 2008; Cox et al. 2009, 2011; Kirchner and Selbach 2012) to process phosphoproteomics data. Alternatively, there are several freely or commercially available software packages (e.g., Mascot, Proteome Discoverer, Scaffold, Trans-Proteomic Pipeline).

Orbital shaker

PEEK MicroCross (Upchurch P-889)

$\mathrm{pH}$ indicator strips

PicoTip nano-emitter, fused silica (pulled, $20-\mathrm{cm} ; 360-\mu \mathrm{m}$ OD $\times 75-\mu \mathrm{m}$ ID; $8-\mu \mathrm{m}$ tip ID [New Objective FS360-75-8-N-5-C15]), and reversed-phase Reprosil-Pur C18-AQ (3- $\mu$ m with 120- $\AA$ pores [Dr. Maisch r13.aq])

The nano-emitter is packed with reversed-phase Reprosil-Pur C18-AQ in Step 33. Prepacked columns are also available-for example, PicoFrit columns (15-cm; 360- $\mu$ OD OD $75-\mu m$ ID; 8- $\mu m$ Tip ID) packed with ReprosilPUR C18 AQ (3- $\mu \mathrm{m} ; 120-\AA)$ (New Objective PF7508-150H354).

Platinum electrode

Pressure injection cell (Next Advance PC77-MAG)

SCX column (Resource S, 1-mL [GE Healthcare 17-1178-01])

Sep-Pak C18 classic cartridge (reversed-phase, 360-mg sorbent [Waters WAT051910])

Thermomixer 
A. Carpy et al.

$\mathrm{TiO}_{2}$ beads (Sachtopore NP, 5- $\mu \mathrm{m}, 300-\AA$ [Sachtleben Chemie SNX 030S005])

Vacuum centrifuge

\section{METHOD}

Performing In-Solution Protein Digestion

Salt concentrations should be kept at a minimum during all steps. Salt concentrations of $>10 \mathrm{~mm}$ may interfere with subsequent SCX chromatography.

1. Dissolve the protein sample in denaturation buffer at room temperature to a final concentration of $2-5 \mathrm{mg} / \mathrm{mL}$.

Do not heat samples in the presence of urea; high concentrations of urea will lead to carbamylation of free amino groups.

2. Add reduction buffer to a final concentration of $1 \mathrm{~mm}$ DTT. Incubate with mild shaking for $1 \mathrm{~h}$ at room temperature.

3. Add alkylation buffer to a final concentration of $5.5 \mathrm{~mm}$ IAA. Incubate with mild shaking for $1 \mathrm{~h}$ at room temperature in the dark.

4. Check the $\mathrm{pH}$ of the sample using a $\mathrm{pH}$ indicator strip and adjust to 8.0 if necessary using a very small volume of $1 \mathrm{~m}$ Tris- $\mathrm{HCl}$ ( $\mathrm{pH} 8.0)$.

5. Add $1 \mu \mathrm{g}$ of lysyl endopeptidase LysC per $100 \mu \mathrm{g}$ of protein. Incubate with mild shaking for $3 \mathrm{~h}$ at room temperature.

6. Dilute the sample 1:5 with Milli-Q $\mathrm{H}_{2} \mathrm{O}$.

7. Add the following reagents.

i. If samples are labeled with lysine and arginine, add $1 \mu \mathrm{g}$ of trypsin per $100 \mu \mathrm{g}$ of protein.

ii. If samples are only labeled with lysine, add another $1 \mu \mathrm{g}$ of lysyl endopeptidase LysC per 100 $\mu \mathrm{g}$ of protein instead of trypsin.

8. Check the $\mathrm{pH}$ of the sample and adjust to 8.0 if necessary. Incubate overnight ( $\sim 18 \mathrm{~h})$ with mild shaking at room temperature.

Sample $\mathrm{pH}$ may change after digestion is completed, and/or after trypsin has been added, as trypsin is stored in acidic conditions.

9. To measure the protein digest directly (proteome measurement) using liquid chromatographytandem mass spectrometry (LC-MS/MS), proceed to liquid chromatography (Step 33). Otherwise, proceed to SCX chromatography (Step 10) followed by $\mathrm{TiO}_{2}$ chromatography (Step 15).

\section{Performing SCX Chromatography}

Most of our published work includes SCX as a prefractionation step in phosphoproteomic sample preparation. However, recent protocols either avoid this step (Soufi et al. 2015) or use alternative peptide fractionation methods, such as high-pH reversed-phase chromatography (Batth et al. 2014). If you are applying an alternative prefractionation protocol, proceed to Step 15 for $\mathrm{TiO}_{2}$ enrichment of peptide fractions.

10. Quench the digestion reaction by adding TFA to a final concentration of $0.1 \%$ (vol/vol). Incubate for $10 \mathrm{~min}$ at room temperature with shaking. Check that the $\mathrm{pH}$ is $<2.7$; if necessary, add more TFA, keeping the concentration as low as possible.

Usually a maximum of $0.3 \%$ TFA is required.

11. Centrifuge the sample for $5 \mathrm{~min}$ at $3000 \mathrm{~g}$ to remove precipitate. Transfer the supernatant to a new tube and discard the precipitate.

The precipitate contains mainly urea.

12. Load the protein digest onto an equilibrated SCX column with SCX solvent A at a flow rate of $1 \mathrm{~mL} / \mathrm{min}$. 
Conductivity during sample loading should be $<4 \mathrm{mS} / \mathrm{cm}$ to avoid interference with peptide binding; if higher conductivity is observed, flowthrough (FT) should be diluted with Milli-Q $\mathrm{H}_{2} \mathrm{O}$ and reloaded onto the column. If preferred, samples can be desalted as described in Step 15 and redissolved in SCX solvent A.

13. Collect the FT for $\mathrm{TiO}_{2}$ chromatography.

Collection and subsequent phosphopeptide enrichment and analysis of the FT is particularly important, because multiply-phosphorylated phosphorylated peptides will not bind to the SCX column.

14. Elute the bound peptides with a linear gradient of 0\%-30\% SCX solvent B for $30 \mathrm{~min}$ at a flow rate of $1 \mathrm{~mL} / \mathrm{min}$. Collect the eluent in $2-\mathrm{mL}$ fractions.

\section{Performing $\mathrm{TiO}_{2}$ Chromatography}

Each SCX fraction, as well as the FT from Step 13, is incubated with separate batches of $\mathrm{TiO}_{2}$ beads.

15. Desalt the peptides in the FT using reversed-phase Sep-Pak C18 cartridges.

The FT fraction contains a high amount of urea.

Each cartridge has a binding capacity of $\sim 18 \mathrm{mg}$ of protein.

16. Lyophilize the FT and each fraction separately.

Drying samples for phosphopeptide enrichment for long periods in the vacuum centrifuge is not recommended. Vacuum centrifuging usually involves an increase in temperature, which could affect some labile phosphorylation events. In addition, drying to completeness usually leads to low recovery of (phospho) peptides from the walls of centrifuge tubes.

Dried peptides can be stored for several weeks at $-80^{\circ} \mathrm{C}$.

17. Redissolve the $\mathrm{FT}$ in $10 \mathrm{~mL}$ of $\mathrm{TiO}_{2}$ loading solution. Redissolve the fractions in $2 \mathrm{~mL}$ of $\mathrm{TiO}_{2}$ loading solution.

Alternatively, the fractions can be adjusted to a final concentration of $80 \%$ ACN and $6 \%$ TFA by adding ACN and TFA directly to the FT and the fractions. Note that the fractions (not the FT) contain $30 \%$ ACN, so a final concentration of $80 \%$ ACN and $6 \%$ TFA can be achieved by adding $7400 \mu \mathrm{L}$ of ACN and $600 \mu \mathrm{L}$ of TFA per fraction for a final volume of $10 \mathrm{~mL}$. The FT has no ACN, and the amount of ACN required must be calculated depending on the FT volume.

18. Prepare $\mathrm{TiO}_{2}$ beads.

i. In a dedicated tube, weigh out $5 \mathrm{mg}$ of $\mathrm{TiO}_{2}$ beads per sample for each round of enrichment. We recommend performing five successive rounds of enrichment of the FT and three of the first five SCX fractions. These fractions usually contain the highest amount of phosphopeptides, and performing serial enrichment of these samples will increase the amount of phosphopeptides identified.

ii. Wash the $\mathrm{TiO}_{2}$ beads by adding $50 \mu \mathrm{L}$ of washing solution per $5 \mathrm{mg}$ of $\mathrm{TiO}_{2}$ beads.

iii. Centrifuge the beads at $10000 \mathrm{~g}$ for $2 \mathrm{~min}$ and discard the supernatant.

iv. Resuspend the beads in $50 \mu \mathrm{L}$ of washing solution per $5 \mathrm{mg}$ of $\mathrm{TiO}_{2}$ beads.

19. Add $50 \mu \mathrm{L}$ of $\mathrm{TiO}_{2}$ beads in washing solution into each sample.

20. Mix the samples for $30 \mathrm{~min}$ at room temperature using an orbital shaker.

21. Centrifuge the samples at $10,000 \mathrm{~g}$ for $2 \mathrm{~min}$, and then remove and keep the supernatant.

22. For successive rounds of enrichment, repeat Steps 19-21 with the supernatant as required. Each successive round of enrichment will generate a new bead sample and should be treated and measured separately.

23. Add $1 \mathrm{~mL}$ of wash solution to the beads. Incubate with shaking at $850 \mathrm{rpm}$ in a Thermomixer for $10 \mathrm{~min}$ at room temperature.

24. Centrifuge the samples at $10,000 \mathrm{~g}$ for $2 \mathrm{~min}$ and discard the supernatant.

25. Repeat Steps 23 and 24 to perform a second wash.

26. Resuspend the beads in $50 \mu \mathrm{L}$ of wash solution and transfer each sample to a $\mathrm{C} 8$ microcolumn.

27. Pack the column at $2000 \mathrm{~g}$ for $3 \mathrm{~min}$ and discard the FT.

28. Elute each sample with $100 \mu \mathrm{L}$ of elution solution. Repeat twice for a total of three elutions. 
A. Carpy et al.

29. Dry the eluates to a final volume of $100 \mu \mathrm{L}$ in a vacuum centrifuge.

30. Add formic acid to a final concentration of $1 \%$.

31. Check that the $\mathrm{pH}$ is $<2.7$.

At this point, samples can be further dried to a final volume of $5 \mu \mathrm{L}$ and measured directly, which may rescue very hydrophilic phosphopeptides.

32. Desalt the peptides by loading them onto a C18 microcolumn as described previously (Rappsilber et al. 2007).

\section{Performing Liquid Chromatography}

33. Pack the PicoTip nano-emitter with $15 \mathrm{~cm}$ of reversed-phase $\mathrm{C} 18$ with methanol at a constant helium pressure of 80 bar using a pressure injection cell.

Alternatively, prepacked columns can be used.

34. Set the system with a liquid junction, with no precolumn and no split, by connecting the column (packed emitter) to a PEEK MicroCross. Attach to the MicroCross the "waste in" and "column out" lines as well as a platinum electrode to supply the spray voltage.

For a more detailed protocol please refer to Schieltz et al. (2006).

TABLE 1. Two data-dependent methods for the analysis of proteomics data

\begin{tabular}{|c|c|}
\hline Parameter & Value \\
\hline \multicolumn{2}{|l|}{ MS (Positive mode) } \\
\hline Automatic gain control target & $1 \mathrm{E} 6$ \\
\hline Microscans & 1 \\
\hline Max ion fill time & $100 \mathrm{msec}$ \\
\hline $\mathrm{m} / \mathrm{z}$ range & $300-1500 \mathrm{~m} / \mathrm{z}$ \\
\hline Resolution & $120,000 @ m / z 400$ \\
\hline \multicolumn{2}{|c|}{ Option 1: data-dependent: MS/MS (HCD) } \\
\hline Automatic gain control target & $4 \mathrm{E} 4$ \\
\hline Microscans & 1 \\
\hline Max ion fill time & $150 \mathrm{msec}$ \\
\hline Resolution & 15,000@m/z 400 \\
\hline Analyze top $N$ peaks & 15 \\
\hline Ion selection threshold & 5000 counts \\
\hline Fixed first mass & $80 \mathrm{~m} / \mathrm{z}$ \\
\hline Activation time & $0.1 \mathrm{msec}$ \\
\hline \multicolumn{2}{|c|}{ Option 2: data-dependent: MS/MS (CID) } \\
\hline Automatic gain control target & 5000 \\
\hline Microscans & 1 \\
\hline Max ion fill time & $25 \mathrm{msec}$ \\
\hline Scan mode & Rapid scan rate \\
\hline Preview mode & Enabled \\
\hline Analyze top $N$ peaks & 10 \\
\hline Ion selection threshold & 2000 counts \\
\hline Activation Q & 0.250 \\
\hline Activation time & $10 \mathrm{msec}$ \\
\hline Multistage activation neutral loss & $-97.97,-48.99$, and -32.66 \\
\hline Multistage activation time & $30 \mathrm{msec}$ \\
\hline \multicolumn{2}{|l|}{ Common settings } \\
\hline Isolation width & $2 \mathrm{~m} / \mathrm{z}$ \\
\hline Normalized collision energy & $35 \%$ \\
\hline Exclude charges & Unassigned and 1+ \\
\hline Dynamic exclusion & $60 \mathrm{sec}$, mass width $10 \mathrm{ppm}$ \\
\hline Electrospray voltage & $1.8-2.3 \mathrm{kV}$ \\
\hline Ion transfer capillary temperature & $275^{\circ} \mathrm{C}$ \\
\hline
\end{tabular}

MS, mass spectrometry; MS/MS, tandem mass spectrometry; HCD, higher-energy collisional dissociation: CID, collision-induced dissociation; $m / z$, mass-to-charge ratio, where $m$ is the mass and $z$ is the number of elementary charges. 
35. Elute the samples from the $\mathrm{C} 8$ microcolumn with $50 \mu \mathrm{L}$ of HPLC solvent $\mathrm{B}$ and dry in the vacuum centrifuge to a final volume of $5 \mu \mathrm{L}$. (If a sample is $<5 \mu \mathrm{L}$, adjust the volume with HPLC solvent A.) Do not let the samples dry and do not use temperature while drying.

36. Add $1 \mu \mathrm{L}$ of HPLC loading solvent to each sample.

37. Load $5 \mu \mathrm{L}$ of a phosphopeptide sample onto the packed PicoTip nano-emitter at a fixed flow rate of $0.7 \mu \mathrm{L} / \mathrm{min}$, limiting pressure to 280 bar using the Intelliflow option.

38. Equilibrate the analytical column with HPLC solvent A.

39. Elute the peptides using a 120 -min linear gradient from 5\%-30\% HPLC solvent B at a flow of $200 \mathrm{~nL} / \mathrm{min}$.

40. Wash out hydrophobic peptides by linearly increasing the concentration of HPLC solvent B to $50 \%$ over 10 min.

41. Wash the column with 90\% HPLC solvent B for 5 min.

42. Equilibrate the column with 5\% HPLC solvent B before next sample is measured.

\section{Performing Mass Spectrometry and Data Processing}

43. Operate the mass spectrometer using data-dependent acquisition mode.

In this mode, a defined number of precursor ions from the survey scan or full MS are selected for further MS/ MS analysis.

44. Analyze the samples using the parameters described in Table 1.

Two data-dependent methods are presented in Table 1. For high-accuracy and full mass range measurements of fragment ions, the HCD method is recommended. The CID MSA method yields fast-scanning and high-sensitivity but low-resolution measurements of fragment ions. We prefer using the HCD method, which usually yields better spectra for modified peptides and facilitates localization of phosphorylation sites due to high accuracy. On some newer instruments, such as the Orbitrap Q-Exactive series, this is also the only available fragmentation method. We recommend use of the CID method in older versions of the Orbitrap instruments (e.g., Orbitrap Classic and Orbitrap XL), because HCD sequencing is considerably slower than CID in these instruments.

Alkylation Buffer (with IAA)

Prepare $550 \mathrm{~mm}$ iodoacetamide (IAA) in $50 \mathrm{~mm}$ ammonium bicarbonate using highpurity, deionized $\mathrm{H}_{2} \mathrm{O}$ (i.e., Milli-Q). Store frozen at $-20^{\circ} \mathrm{C}$.

\section{Denaturation Buffer}

$6 \mathrm{~m}$ urea

2 м thiourea

$1 \% n$-Octylglucoside (w/v)

Combine the reagents listed above in $10 \mathrm{~mm}$ HEPES buffer ( $\mathrm{pH} 8.0$ ) made with high-purity, deionized $\mathrm{H}_{2} \mathrm{O}$ (i.e., Milli-Q). Store frozen at $-20^{\circ} \mathrm{C}$.

\section{Elution Solution}

$40 \% \mathrm{NH}_{4} \mathrm{OH}$ (aq, $25 \% \mathrm{NH}_{3}$ ) $60 \%$ acetonitrile $(\mathrm{ACN})(\mathrm{pH}>10.5)$

Combine the reagents listed above in high purity, deionized $\mathrm{H}_{2} \mathrm{O}$ (i.e., Milli-Q). Store up to 4 wk at room temperature. 
A. Carpy et al.

HPLC Loading Solvent

$1 \%$ trifluoroacetic acid (TFA)

$2 \%$ acetonitrile $(\mathrm{ACN})$

Combine the reagents listed above in high-purity, deionized $\mathrm{H}_{2} \mathrm{O}$ (i.e., Milli-Q). Store up to 4 wk at room temperature.

\section{HPLC Solvent A}

Prepare $0.5 \%$ formic acid in high-purity, deionized $\mathrm{H}_{2} \mathrm{O}$ (i.e., Milli-Q). Store up to 4 wk at room temperature.

\section{HPLC Solvent $B$}

$0.5 \%$ formic acid

$80 \%$ acetonitrile $(\mathrm{ACN})$

Combine the reagents listed above in high purity, deionized $\mathrm{H}_{2} \mathrm{O}$ (i.e., Milli-Q). Store up to 4 wk at room temperature.

\section{Reduction Buffer (with DTT)}

Prepare $1 \mathrm{~m}$ dithiothreitol (DTT) in $50 \mathrm{~mm}$ ammonium bicarbonate using high-purity, deionized $\mathrm{H}_{2} \mathrm{O}$ (Milli-Q). Store frozen at $-20^{\circ} \mathrm{C}$.

\section{SCX Solvent A}

$5 \mathrm{~mm}$ potassium dihydrogen phosphate

$30 \%$ acetonitrile $(\mathrm{ACN})$

Combine the reagents listed above in high-purity, deionized $\mathrm{H}_{2} \mathrm{O}$ (i.e., Milli-Q). Acidify with trifluoroacetic acid (TFA) to $\mathrm{pH}$ 2.7. Store up to $4 \mathrm{wk}$ at room temperature.

\section{SCX Solvent B}

$5 \mathrm{~mm}$ potassium dihydrogen phosphate

$30 \%$ acetonitrile (ACN)

$350 \mathrm{~mm}$ potassium chloride

Combine the reagents listed above in high-purity, deionized $\mathrm{H}_{2} \mathrm{O}$ (i.e., Milli-Q). Acidify with trifluoroacetic acid (TFA) to $\mathrm{pH}$ 2.7. Store up to $4 \mathrm{wk}$ at room temperature.

\section{$\mathrm{TiO}_{2}$ Loading Solution}

$80 \%$ acetonitrile $(\mathrm{ACN})$

$6 \%$ trifluoroacetic acid (TFA)

Immediately before use, combine the reagents listed above in high-purity, deionized $\mathrm{H}_{2} \mathrm{O}$ (i.e., Milli-Q).

\section{Washing Solution for $\mathrm{TiO}_{2}$ Beads}

$80 \%$ acetonitrile $(\mathrm{ACN})$

$0.1 \%$ trifluoroacetic acid (TFA)

Immediately before use, combine the reagents listed above in high-purity, deionized $\mathrm{H}_{2} \mathrm{O}$ (i.e., Milli-Q). 
Our work is supported by funding from the Juniorprofessoren-Programm of the BW-Stiftung, and SFB 766 of the German Research Council (DFG) to B.M. and by a Wellcome Trust grant (094517) to K.E.S., A.K., and S.H. received funding from SFB 446 of the German Research Council (DFG) and the Max Planck Society. W.E.B. was supported by a Cancer Research UK PhD Studentship (C20060/ A10789). The Wellcome Trust Centre for Cell Biology is supported by core funding from the Wellcome Trust (092076).

\section{REFERENCES}

Batth TS, Francavilla C, Olsen JV. 2014. Off-line high-pH reversed-phase fractionation for in-depth phosphoproteomics. J Proteome Res 13: 6176-6186.

Cox J, Mann M. 2008. MaxQuant enables high peptide identification rates, individualized p.p.b.-range mass accuracies and proteome-wide protein quantification. Nat Biotechnol 26: 1367-1372.

Cox J, Matic I, Hilger M, Nagaraj N, Selbach M, Olsen JV, Mann M. 2009. A practical guide to the MaxQuant computational platform for SILACbased quantitative proteomics. Nat Protoc 4: 698-705.

Cox J, Neuhauser N, Michalski A, Scheltema RA, Olsen JV, Mann M. 2011. Andromeda: A peptide search engine integrated into the MaxQuant environment. J Proteome Res 10: 1794-1805.

Kirchner M, Selbach M. 2012. In vivo quantitative proteome profiling: Planning and evaluation of SILAC experiments. Methods Mol Biol 893: 175-199.
Koch A, Bicho CC, Borek WE, Carpy A, Maček B, Hauf S, Sawin KE. 2016 Construction, growth, and harvesting of fission yeast table isotope labeling by amino acids in cell culture (SILAC) strains. Cold Spring Harb Protoc doi: 10.1101/pdb.prot091678.

Rappsilber J, Mann M, Ishihama Y. 2007. Protocol for micro-purification, enrichment, pre-fractionation and storage of peptides for proteomics using StageTips. Nat Protoc 2: 1896-1906.

Schieltz DM, Washburn MP, Hays LG. 2006. Analysis of complex protein mixtures using nano-LC coupled to MS/MS. Cold Spring Harb Protoc 2006: pdb.prot4553.

Soufi B, Krug K, Harst A, Maček B. 2015. Characterization of the E.coli proteome and its modifications during growth and ethanol stress. Front Microbiol 6: 103. 


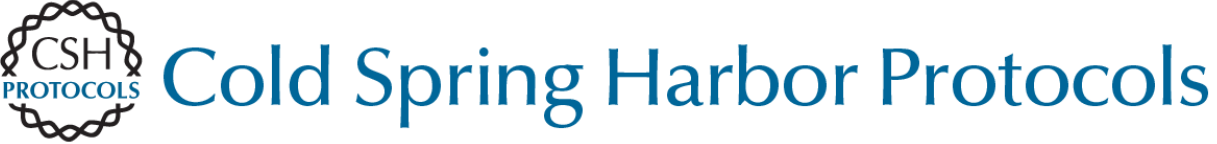

\section{Stable Isotope Labeling by Amino Acids in Cell Culture (SILAC)-Based Quantitative Proteomics and Phosphoproteomics in Fission Yeast}

Alejandro Carpy, André Koch, Claudia C. Bicho, Weronika E. Borek, Silke Hauf, Kenneth E. Sawin and Boris Macek

Cold Spring Harb Protoc; doi: 10.1101/pdb.prot091686

\begin{tabular}{|c|c|}
\hline $\begin{array}{r}\text { Email Alerting } \\
\text { Service }\end{array}$ & Receive free email alerts when new articles cite this article - click here. \\
\hline $\begin{array}{r}\text { Subject } \\
\text { Categories }\end{array}$ & $\begin{array}{l}\text { Browse articles on similar topics from Cold Spring Harbor Protocols. } \\
\text { Analysis of Protein Expression in Cultured Cells (57 articles) } \\
\text { Chromatography ( } 47 \text { articles) } \\
\text { Liquid Chromatography ( } 51 \text { articles) } \\
\text { Mass Spectrometry (78 articles) } \\
\text { Metabolic Labeling and Protein Modification ( } 21 \text { articles) } \\
\text { Proteins and Proteomics, general (575 articles) } \\
\text { Proteome Analysis (56 articles) } \\
\text { Yeast (288 articles) }\end{array}$ \\
\hline
\end{tabular}

